\title{
Inhalt
}

Vorwort - IX

\section{Teil I: Einleitung}

Volker Arnke, Michael Rohrschneider und Siegrid Westphal

Die Wiederherstellung des Friedens. Einführende Betrachtungen - 3

Guido Braun

Vom Frieden zum Krieg und vom Krieg zum Frieden. Frühneuzeitliche

Perspektiven der Historischen Konflikt- und Friedensforschung - 15

Teil II: Vom Frieden zum Krieg und Frieden im Krieg

Maria-Elisabeth Brunert

Wendepunkte auf dem Weg in den Dreißigjährigen Krieg 1618/19 37

Volker Arnke

Eger - Lübeck - Prag - Köln - Goslar. Verhandlungen und Verträge zwischen

Frieden und Krieg 1619-1642 - 57

Teil III: Vom Krieg zum Frieden - Parteien und Verhandlungsführung auf dem Westfälischen Friedenskongress

\section{III.A: Verhandlungsführung}

Markus Laufs

Translativ - diskursiv - regulativ. Praktiken päpstlich-venezianischer

Mediation auf dem Westfälischen Friedenskongress und ihre

Funktionen -83 


\section{Alexander Gerber}

„Viel ungereimbtes dings“? Argumentationsstrategien reichsständischer

Gesandter auf dem Westfälischen Friedenskongress im Vergleich — 107

\section{III.B: Kompromisslose Parteien}

Dorothée Goetze

Frieden um (fast) jeden Preis. Die Politik Ferdinands III. (1608-1657) in der Schlussphase des Westfälischen Friedenskongresses zwischen

Rollenkonkurrenz, Prinzipientreue und dogmatischem Pragmatismus - 131

Lena Oetzel

Prinzipientreue und selbstgewählte Isolation. Kursachsen auf dem Westfälischen Friedenskongress — 155

\section{III.C: Die kompromissbereite Partei und ihre Verhandlungen}

\section{Maria-Elisabeth Brunert}

Der Begriff „Dritte Partei“ in Quellen und Sekundärliteratur zum Westfälischen Friedenskongress — 179

Volker Arnke

Zwischen Vermittlung, Reichs- und Eigeninteressen. Zur Rolle und zum Selbstverständnis der „Dritten Partei“ des Westfälischen Friedenskongresses -193

Dorothée Goetze

„Was grosse vermessenheit“. Die Verhandlungen der sogenannten Dritten Partei aus Perspektive der kaiserlichen Gesandten — 213

Christoph Nonnast

Fluide Kooperationen. Sachsen-Altenburg, Schweden und die verständigungsbereiten Reichsstände in der Endphase des Westfälischen Friedenskongresses -237

\section{Siegrid Westphal}

Reichsstädtisches Agieren und Argumentieren bei den Verhandlungen des Westfälischen Friedenskongresses — 261 
Guido Braun

Die Dritte Partei als Faktor der französischen Außen- und Reichspolitik im späten 17. Jahrhundert — 275

Verzeichnis der Autorinnen und Autoren — 293

Personenregister -295

Ortsregister -299 
